\title{
Adolescence and Development: Clinical Psychology and Psychoanalysis
}

\author{
Edgar Alfonso Acuña Bermúdez* \\ University of San Buenaventura-Cartagena, Colombia
}

Submission: September 12, 2020; Published: November 03, 2020

*Corresponding author: Edgar Alfonso Acuña Bermúdez, University of San Buenaventura-Cartagena, Colombia

\begin{abstract}
The passage through the adolescent period is somewhat messy and never in a straight line. In general terms, adolescence extends from the moment of sexual maturity until the age at which independence from the authority of the adult is ensured by law. In truth, the attainment of the goals in mental life that characterize the different phases of the adolescent period are often contradictory in their direction and also qualitatively heterogeneous; that is, this progression, digression, and regression alternate in evidence, since they temporarily comprise antagonistic goals. Regarding the choice of adolescent object, the mental and physical state that is generally associated with adolescence (both early adolescence and adolescence proper) has very different qualities from the pre-adolescent phase. The stage of body image representation in adolescence is important, since it is at this stage where the adolescent is faced with physical changes (growth of sexual organs, increased hormonal activity, reproductive capacity, among others), changes intellectual or emotional (ability to make self-value judgments, etc.) and three crises: identity, authority and sexual, fundamental aspects that influence the perception of their body. During adolescence proper, there is a decisive shift toward heterosexuality and a final and irreversible renunciation of the incestuous object.
\end{abstract}

Keywords: Adolescence; Psychoanalysis; Crisis, Choice of object; Impulses; Genitality

\section{Introduction}

The word adolescence comes from the Latin verb adoleceré, which means to grow or reach maturity. This means not only physical growth but also mental development. In the somatic aspect it represents reaching an adult stature, the acquisition of physical characteristics characteristic of the adult individual, and the development of the reproductive system that makes procreation possible, according to Hurlock E [1].

Therefore, adolescence should not be confused with "puberty" which is the period of preadolescence and early adolescence in which sexual maturation occurs. Puberty is a part of adolescence, but it is not synonymous with it, since adolescence, as it is now understood, includes all phases of maturation, and not only that of physical appearance [2].

In general terms, adolescence extends from the moment of sexual maturity until the age at which independence from the authority of the adult is ensured by law. Because there are such striking individual differences in the ages at which sexual maturity is reached, it is difficult to do more than demarcate the end of childhood and the beginning of adolescence by using average ages.
The difference according to sex shows that boys mature somewhat later than girls, we can consider that their preadolescence extends from 11 to 12 and a half or 13 years, the initial period of adolescence from 13 to 17 , and the final from 18 to 21 . In the case of girls, pre-adolescence is usually between 10 and 11 years, the initial period of adolescence between 12 and 16 years and the end between 17 and 20 or 21 However, within each sex there can be pronounced individual differences, this is important due to the close relationship that exists between the individual's behavior and the level of their sexual development.

The passage through the adolescent period is somewhat messy and never in a straight line. In truth, the attainment of the goals in mental life that characterize the different phases of the adolescent period are often contradictory in their direction and also qualitatively heterogeneous; that is, this progression, digression, and regression alternate in evidence, since they temporarily comprise antagonistic goals. Adaptive and defensive mechanisms are interwoven, and the duration of each of the phases cannot be fixed by a specific time or by a reference to chronological age. This extraordinary elasticity of the psychological movement, which 
underlines the spectacular diversity of the adolescent period, cannot be overemphasized; however, the fact remains that there is an orderly sequence in psychological development and that it can be described in terms of more or less distinct phases.

The adolescent can go through the different phases very quickly or can work out one of them in endless variations; but in no way can it deviate from the essential psychic transformations of the different phases. Its elaboration by the process of development differentiation over a certain period of time, results in a complex structure of the personality; a somewhat stormy passage through adolescence usually produces an imprint in the adult that is described as primitivization. Neither of these two developments should be confused with levels of maturation; rather they are evidence of degrees of complexity and differentiation. Both the innate drive forward and the growth potential of the adolescent personality seek to integrate at the level of maturation of puberty and the old modalities to maintain balance. Through this process of integration, continuity in the experience of the self is preserved, which facilitates the emergence of a sense of stability in being - or sense of identity.

The importance of the latency period to be successful at initiation and during adolescent development. the latency period provides the child with the instruments, in terms of ego development, that prepare him to cope with the increased impulses at puberty. The child, in other words, is ready for the test of distributing the energy influx at all levels of personality functioning, which were worked out during the latency period. Hence, he is able to divert instinctual energy to differentiated physical structures and different psychological activities, rather than experiencing this only as an increase in sexual and aggressive tension. Freud [3] refers to abortive latency as "spontaneous sexual precocity" which is due to the fact that the latency period could not be established successfully; therefore he thought that "sexual inhibitions" that constitute the essential component of the latency period, were not adequately acquired, "causing sexual manifestations, which, because sexual inhibitions were incomplete and that on the other hand the genital system is not developed, they can be oriented towards perversions. "

During the preadolescent phase, a quantitative increase in instinctual pressure leads to an indiscriminate cathexis of all those aggressive and libidinal goals of gratification that have served the child during the early years of his life. You cannot distinguish a new love object and a new instinctual goal. Any experience can be transformed into sexual stimulation - even those thoughts, fantasies and activities that are devoid of obvious erotic connotations. For example, the stimulus to which the preadolescent boy reacts with an erection; It is not specifically or necessarily an erotic stimulus that causes genital arousal, but it can be caused by fear, anger, or by a general arousal. The first emissions during wakefulness are often due to these affective like this one, rather than to specific erotic stimuli. Among the more physically mature boys, competitive situations, such as wrestling, have been reported as triggering spontaneous emissions. This state of affairs in the boy entering puberty is a sign that genital function acts as a nonspecific discharge of tension; this is characteristic from childhood to adolescence when the organ gradually acquires exclusive sensitivity to heterosexual stimulation.

The resurgence of genital drives does not manifest itself uniformly among boys and girls because each sex deals with the rising pubertal drives in a different way. Erickson [4] described such a clear difference in adolescent play constructions. It is apparent from his material that the theme of masculinity and femininity leads to different configurations in the play of boy and girl. It is the concern (conscious and preconscious) with the sexual organs, their function, integrity and protection, and not their relationship with love situations and their satisfaction that stands out in preadolescent play constructions. Erickson comments: "The most significant sexual differences in the game give us the following picture: in boys the most salient variables are height, fall and movement and their channeling or arrest (police), in girls, static interiors that are open, simply locked up or blocked and they are raped. "

In general terms we can say that a quantitative increase in drives characterizes preadolescence and that this condition leads to a resurgence of pregenitality [5]. This innovation leads the latency period to its completion, the child is more inaccessible, more difficult to teach and control. Everything that has been obtained through education in previous years in terms of instinctual control and social conformity seems to be on the way to destruction.

It is a well-known fact that psychological development in preadolescence is different in girls and in boys. The differences between the sexes are very significant; descriptive psychology has paid great attention to this period and has accumulated a large number of observations. The boy takes a route towards genital orientation through the cathexis of his pregenital impulses; on the contrary, the girl is directed more directly towards the opposite sex [6].

Pre-adolescent boy fantasies are usually well protected; those that are most easily mentioned are those of syntonic thoughts to the self of grandeur and indecency.

Since we have defined the organization of impulses in preadolescence in terms of pre-Oedipal positions, consider the first analysis of a young adolescent named Dora [3]. Dora was 16 when she visited Freud and 18 when she began her treatment. The material from the story, which we will review here, concerns the pre-adolescent organization of impulses in this young woman. His pre-oedipal maternal fixation proved to be pathogenic in intensity and represented an invincible obstacle on the road to the progressive development of adolescence.

Regarding the choice of adolescent object, the mental and physical state that is generally associated with adolescence (both 


\section{Global Journal of Intellectual \& Developmental Disabilities}

early adolescence and adolescence proper) has very different qualities from the pre-adolescent phase. The difference shows itself in a much richer emotional life, in an orientation aimed at growth, in an invincible attempt to define oneself in response to the question: "Who am I?" The problem of object relations comes to the fore, as a central theme, and its variations color the whole of psychological development in the two subsequent phases. What differentiates this period from preadolescence is, therefore, the merely quantitative change in impulses. The abandonment of the preadolescent regressive position is very noticeable. Pregenitality increasingly loses the role of a satisfactory function, being relegated to an initiation activity - mental and physical - and gives rise to the emergence of a new instinctual component, precisely the anticipation of pleasure. This change in the hierarchical organization of impulses and their definitive and irreversible character represents an innovation that has a decisive influence on the development of the ego. The ego, as it were, takes its signals from these changes in instinctual organization and elaborates in its structure a hierarchical organization in its functions and in its defensive patterns. Both acquire at the end of adolescence an irreversible fixation called character; This firm structure which emerges from these phases - which is actually built on the achievements of the latency period - will not be completed until the post-adolescent phase.

While the differentiation between preadolescence and the two phases that follow is quite clear, some justification is necessary to present "early adolescence" and "adolescence proper" as two separate entities. On strictly observational grounds, this definition is justified, because after preadolescence a period of repeated attempts to separate from primary love objects becomes very apparent. In early adolescence there is a resurgence of idealized friendships with members of the same sex; sustained interests and creativity are kept low and the somewhat clumsy search for new values - not simply opposition - emerges; In short, there is a transition phase, which has its own characteristics before adolescence takes hold.

During adolescence proper, there is a decisive shift toward heterosexuality and a final and irreversible renunciation of the incestuous object. Certain types of defenses, such as intellectualization and asceticism, belong to the phase of adolescence proper. In general, a tendency towards internal experience and self-discovery becomes very noticeable, hence the religious experience and the discovery of beauty in all its manifestations. We recognize that this development is a form of sublimation of the child's love for the idealized parent and a consequence of the eventual renunciation of early love objects. The feeling of "being in love" and the preoccupation with political, philosophical and social problems is typical of adolescence. The frank break with the childhood way of life occurs in this phase; The late adolescent years are tasked with testing these new and far-reaching accomplishments by integrating them into the total experience of life.
In establishing the two phases of early adolescence and adolescence proper, I agree that Deutsch [7] divides adolescence for women into "early puberty" and "puberty and adolescence." In this last phase, which he also calls "advanced puberty," heterosexual tendencies are characteristic. I emphasize the characteristic that unifies them, mainly when separating from the object and seeking another, for example the definitive change towards a separation from the family and the hierarchical organization of impulses and functions of the self. The essential ingredient of both phases is the awareness of the social situation with anguish and guilt.

The central problem of early adolescence and adolescence proper lies in a series of predicaments about object relations. The solution to this problem depends on the many variations this theme goes through over the years; These variations ultimately determine adulthood in a genuine or spurious way. These variations are somewhat reminiscent of childhood, we just have to remember that the child's need to be loved only gradually merges with the need to give; the need to have things done for me becomes "doing things for someone else." The passive role of being controlled is gradually and partially replaced by the child's need for active control of the external world. This polarity of activity and passivity reappears during adolescence as a crucial problem. The ambivalence so characteristic of adolescence includes not only goals. instinctive, active and passive this is equally true for men and women. The rebellion against the superego in the adolescent male often represents opposition against passive feminine tendencies that were an essential part of the boy's oedipal relationship with his father. Freud [8] formulates this problem in relation to adolescence in the following way: "it is not until the completion of development during the period of puberty that the polarity of sex coincides with the masculine and feminine. activity and possession of the penis; the feminine object is passivity. The vagina is valued as an asylum for the penis, it is an inheritance from the maternal womb ".

During early adolescence and adolescence proper, the renunciation of primary objects of love, parents as sexual objects, must be achieved; siblings and paternal substitutes must be included in this process of renunciation; these phases are essentially related to the renunciation of objects and the search for others. These processes reverberate in the ego, producing cathectic changes that influence both existing object representations and self-representations. Due to this the sense of identity acquires from now on an unknown lability.

During early adolescence and adolescence proper, impulses shift toward genitality, libidinal objects shift from pre-Oedipal and Oedipal to non-incestuous heterosexual objects. The selfsafeguards its integrity through defensive operations; Some of these are restrictive for the ego and require a cathectic energy for their maintenance, while others show to be adaptive in nature to allow the discharge of inhibited impulses (sublimation); These become the permanent regulators of self-esteem [9]. 
After the discovery of infantile sexuality ("three essays on a sexual theory") [3] adolescence came to be considered as a stage of final transformation or as a simple bridge between infantile sexuality and adult-centered sexuality. genitality. Later Ernest Jones [10] affirms that adolescence recapitulates childhood and that the way in which a certain person has to go through the necessary stages of adolescent development is largely determined by the pattern of his childhood development.

Returning to the phrase of Lacan [11] I would say that the adolescent's symptom is in a position to respond to what is symptomatic not only in the family structure, but also in the social one. The adolescent oscillates between preserving attitudes of a child, dependent on the parents, and arriving at an adult position, to finally conquer his external autonomy, outside the family structure. But the current adolescent drama is that society does not facilitate this take-off, rather it hinders it. In the past, without going very far in time, adolescents had the obstacle, I would say almost natural, of the family, in those that impeded or did not accompany their transition to independence. Parents who, due to their own conflict and / or that of the couple, did not accept the drama of the passage of time and its vicissitudes, of the son who ceases to be a child, who can leave home, with all that this entails for the couple. Today a macro-obstacle is added: society.

Courtship is one of the most beautiful and enjoyable stages of human life. In the courtship, one goes from mere sympathy or simply "liking each other" to a new relationship of greater knowledge and that in turn must be inspired by the spirit of dedication, understanding, respect, and delicacy.

There are many types of courtship, some are lived as a game, others are closer and deeper. Before reaching the courtship, they go through several stages:

- The stage of attraction and enchantment.

- $\quad$ The stage of friendship, where feelings of closeness begin to be experienced and the norms and scope of the relationship are defined.

- $\quad$ Beginning of the courtship: at this stage both recognize that they are attracted and decide to start a relationship, which becomes even closer, full of details, with certain limits and where true love can flourish.

In courtship there is attraction and falling in love, hence the person behaves differently: He often thinks of the loved one, whom he idealizes and marvels, he wants to see the person at all times, be together and talk, he seeks the way to please someone you love, there are intense feelings and emotions in the face of the real or imagined presence of the loved one, the person seeks to support his partner and wishes his good.

It is almost unnecessary to mention that good communication is the foundation of a successful relationship. Communication is not always verbal since the couple also looks at each other, touches each other, smiles (non-verbal communication). Faced with a situation in which we want to communicate something, the way or form of emitting it, how the other receives it and the content of this message are fundamental. Thus, we find different ways of communicating and some of them are not exactly positive.

"Coercion": it is a form of communication where only our own needs are taken into account, making life very difficult for the other in the sense that their needs are not taken into account and trying to achieve the submission or cancellation of the other.

This is so because the partner who gives in does so not because he considers that the other is right but to avoid discussion and threats. In conclusion: to escape a conflict.

Healthy jealousy involves worrying about the fear of losing a loved one, because they have a real or imaginary relationship with someone. Pathological jealousy is accompanied by intense feelings of insecurity, self-pity, hostility, and depression and is often destructive to the relationship.

One of the most frequent conflicts in couple relationships is the different perspective of both members to organize their free time and social activities.

Faced with the question posed, the different psychological and sociological research and studies converge on the same result: the absence of the father in the children's lives has, in the vast majority of cases, generates negative repercussions that are manifested in different levels of adjustment adaptive of children. The incidence of these consequences is modulated by multiple factors. We can cite, as the most significant, the age of the minors in which the deprivation of parental presence begins and the duration of it, the causes that originate it, the sex of the children, psychological variables of the children and factors the environment of a family, social, cultural and economic nature.

Adolescents suffer the most in the short term from insecurity, loneliness, and depression, which can manifest itself in the form of school failure, criminal behavior, drug use and vagrancy. Adolescents and young adults keep memories alive at 10 years of their parents' divorce, causing them to express distress about their love relationships and possible marital failure. The repercussions on adolescents also depend on the psychosocial stressors that can accompany divorce.

From the point of view of the consequences, psychological research on the effects of the absence of the father in the lives of the children has focused mainly on three large groups of variables: Effects on school adjustment, cognitive development and levels of children's intellectual competence, pisco-sexual development and their psychological, behavioral and social adjustment.

Studies on the effects of the father on the psychological and emotional stability of children point to the conclusion that parental deprivation is associated with a greater probability that children present emotional disorders at different stages of their evolutionary development. 
The stage of body image representation in adolescence is important, since it is at this stage where the adolescent is faced with physical changes (growth of sexual organs, increased hormonal activity, reproductive capacity, among others), changes intellectual or emotional (ability to make self-value judgments, etc.) and three crises: identity, authority and sexual, fundamental aspects that influence the perception of their body [12].

All these changes in the adolescent can lead to a feeling of anxiety for not knowing what are the changes that will be generated soon in his body and how to handle or perceive them; Of course, these emotions appear more intensely in some adolescents than in others.

It is important to work on the adolescent's body image, since if they do not have an adequate orientation regarding it, they can present complexes, frustrations, social isolation, among others, in later stages of their life.

The representation of the body scheme is important for all people since it is a fundamental component to build their own personality and to affirm themselves in relation to others.

The innate ability of the infant appears with the experience that only unfolds from a specific stimulus such as that of the paternal function in the first years of life to be able to build a coherent communication with other subjects the paternal function establishes the law and this allows think reasonably and order information from the imaginary and the real [13].

The human being with his language can not only communicate but also reflect and learn about the experiences of others and transmit his own, Berenstein I [14]. The ability of human beings to communicate can enrich their experiences and their life. Teenage pregnancy affects her life, her child, the family and social environment and, due to its frequency, has become a public health problem.

Pregnancy is a profound experience in a woman's life, as her body and mood change, so do her needs and priorities. This transition, which is challenging for adults, can be overwhelming for a teenager.

Those who believe that single mothers can have their children is because women have proven to be capable of that and more, they see single mothers as a courageous act because it means that they are daring to challenge the puritanism of a macho society and this deserves respect of the society. However, in the circumstances of today's deteriorating society, an act of true courage would be to have the courage to unite, with the commitment to do everything possible to form a stable and harmonious couple that forms a warm home where children and wives daughters can enjoy the innumerable benefits that growing in the love of both parents brings them.

Sexuality is a source of communication and is expressed mainly in three areas: genital or biological, which it expresses in physiological aspects; erotic area, related to the search for pleasure; and the moral expressed in the social structure fixed in the values or accepted norms.

Pregnancy in a young couple, in general, is an unexpected, surprising event. González points out that "anxiety reactions typical of the moment and disorders develop in the normal process of personality development, phenomena that condition the appearance of organic pathologies typical of pregnancy.

A woman with emotional deprivation and without an adequate education of the will, in addition to environmental eroticization and the pseudo-valuation of sexuality without compromise, may lead the young woman to an immature sexual relationship with the risk of an unexpected pregnancy. Many women go into pregnancy as a way to fill their many gaps. Being sexually required makes them feel valued. They give that affection not so much for personal satisfaction, but to satisfy the person they want to keep by their side.

In the 1960s Jacques Lacan already said, “... the child's symptom is in a position to respond to what is symptomatic in the family structure ..." It is known that the symptom is a metaphor, like a cave painting to be deciphered and that keeps a meaning Not being any cipher, the symptom is a text that speaks of a truth that the subject does not know, or that in any case knows partially and entails suffering.

\section{Conclusion}

Adolescence as what one suffers from, in the sole sense of suffering. From the knowledge disclosed by Freud, the question must be taken up at puberty: the second sexual awakening, the second time of finding the object. "... With the advent of puberty, the transformations that have to lead the infantile sexual life towards its definitive normal constitution begin. The sexual instinct, until then predominantly autoerotic, finally finds the sexual object ..." Awakening second, where the pubescent is with his sexual organ, suitable for the encounter with the other sex, in the possibility of intercourse that transforms him into a producer, a giver of a child. Therefore, adolescence is also the possibility of the passage from being a son to being a father, or being captured there, in the position of a son.

Unlocking from the son position, even in its power, that changes the position in life: it is the opening of the path of one's own desire. Adolescence opens the game of what is possible from one person or the alignment in the ghost of the Other. "The less soldier the ghost of the Subject, the clearer its place of object in the ghost of the parents, the mother more usually or the father ..."

That is why it is the so common interview with parents who come to consult a teenager who is not doing well and when listening sharpened, it is found that they are the ones who do not support the natural changes of the child, the new transit of this child. 


\section{References}

1. Hurlock E (1970) Psychology of adolescence Buenos Aires: Paidós.

2. Klein M (1922) Inhibitions and difficulties in puberty. Complete works. Barcelona: Editions Hormé.

3. Freud S (1905) three essays on a sexual theory. Vol. VII. Complete Works. Buenos Aires: Amorrortú.

4. Erickson (1956) On Adolescence. New York: Free Press.

5. Freud A (1936) Psychoanalysis of child development and teenager. Buenos Aires: Editorial Paidós.

6. Acuña Bermúdez E (2017) Adolescence and psychoanalysis Düsseldorf: Editorial advertisement.

7. Deutsch H (1994) The psychology of women. Buenos Aires: Losada.
8. Freud S (1915) The burial of the Oedipus complex. Vol.XIX. Complete Works. Buenos Aires: Amorrortú.

9. Acuña Bermúdez E (2016) Basics of dynamic clinic and psychoanalysis. Cartagena- Colombia: Editorial Bonaventuriana.

10. Jones E (1922) Some problems of adolescence. Londres: Caliban Book. 11. Lacan J (1960) The identification. Seminar 9. Buenos Aires: Paidós.

12. BLOS P (1986) Psychoanalysis of adolescence. Mexico: Editorial Moritz.

13. Lacan J (1958) The Paternal Metaphor I. Seminar 5. Buenos Aires: Paidós.

14. Berenstein I (1989) Psychoanalysis of the family structure. Editorial Paidós: Buenos Aires.

Your next submission with Juniper Publishers will reach you the below assets

- Quality Editorial service

- Swift Peer Review

- Reprints availability

- E-prints Service

- Manuscript Podcast for convenient understanding

- Global attainment for your research

- Manuscript accessibility in different formats ( Pdf, E-pub, Full Text, Audio)

- Unceasing customer service

Track the below URL for one-step submission https://juniperpublishers.com/online-submission.php 